\title{
PENGARUH MODEL PEMBELAJARAN 5E TERHADAP PERUBAHAN KONSEP TENTANG HUKUM NEWTON PADA SISWA KELAS X SMA NEGERI 6 PALU
}

\author{
Fitriani Yusuf, Jusman Mansyur dan Fihrin \\ yusuf.fitriani@ymail.com \\ Program Studi Pendidikan Fisika FKIP Universitas Tadulako \\ Jl. Soekarno Hatta Km. 9 Kampus Bumi Tadulako Tondo Palu - Sulawesi Tengah
}

\begin{abstract}
Penelitian ini bertujuan mengetahui ada tidaknya pengaruh model pembelajaran $5 \mathrm{E}$ terhadap perubahan konsep tentang hukum Newton pada siswa Kelas X SMA Negeri 6 Palu. Desain penelitian adalah "The Non Equivalen Pretest-Posttest Design". Populasi penelitian adalah seluruh siswa $(n=84)$ kelas $X$ pada SMA Negeri 6 Palu. Pengambilan sampel dilakukan secara purposive sampling dengan sampel penelitian adalah kelas $X_{D}\left(n=14\right.$ sebagai kelas eksperimen) dan Kelas $X_{C}(n=16$ sebagai kelas control). Instrumen penelitian adalah tes pemahaman konsep dan lembar observasi. Pengujian hipotesis dilakukan dengan menggunakan statistik nonparametrik dengan uji U Mann-Whitney pada taraf signifikansi 0,05. Hasil penelitian menunjukkan bahwa terdapat pengaruh model pembelajaran 5E terhadap perubahan konsep Hukum Newton siswa SMA Negeri 6 Palu.
\end{abstract}

Kata Kunci: model pembelajaran $5 \mathrm{E}$, perubahan konsep.

\section{PENDAHULUAN}

Fisika adalah ilmu pengetahuan yang mempelajari kejadian-kejadian yang ada, baik yang dapat diamati secara langsung maupun tidak langsung. Pada awalnya, siswa sudah membawa konsep awal yang disebut prakonsepsi ${ }^{[1]}$. Prakonsepsi merupakan konsep awal yang dibawa oleh siswa sebelum siswa mendapat pembelajaran formal di sekolah dan biasanya dipengaruhi oleh lingkungan sekitarnya. Prakonsepsi ini dapat sesuai dengan konsep ilmiah dan dapat juga tidak sesuai dengan konsep ilmiah. Hanya saja prakonsepsi ini kurang lengkap sehingga prakonsepsi ini perlu dikembangkan dan dibenahi didalam pembelajaran formal atau dengan kata lain perubahan konsep.

Jika perubahan konsep akan terjadi, mulamula anak itu harus merasa tidak puas dengan gagasan yang ada ${ }^{[2,3]}$. Ketidakpuasan anak akan gagasan yang dimilikinya terjadi pada waktu ia dihadapkan pada suatu gagasan baru yang bertentangan dengan gagasan yang dimilikinya, yaitu fase "dihadapkan pada situasi konflik" [1]. Untuk melibatkan terjadinya suatu konflik pada anak agar akhirnya gagasan lama diganti dengan gagasan baru, diperlukan suatu model pembelajaran bagi guru yang sesuai dan tepat agar dapat berlangsung perubahan konseptual pada siswa di dalam kelas.

Penelitian tentang perubahan konseptual menyimpulkan bahwa seorang siswa benar-benar berkembang dalam memahami konsep-konsep fisika hanya dengan perubahan konseptual, baik yang memperluas konsep ataupun meluruskan konsep yang tidak tepat ${ }^{[4]}$.

Model pembelajaran 5E merupakan salah satu model pembelajaran dengan pendekatan konstruktivis ${ }^{[5]}$. Model pembelajaran 5E terdiri dari 5 tahap yaitu engagement (pembangkit minat), exploration (eksplorasi), explanation (penjelasan), elaboration (elaborasi), dan evaluation (evaluasi).

Berdasarkan penelitian sebelumnya, menunjukkan bahwa model pembelajaran $5 \mathrm{E}$ dapat meningkatkan pemahaman konsep siswa $^{[6]}$ dan dapat dapat meningkatkan penguasaan konsep fisika ${ }^{[7]}$.

Berdasarkan uraian di atas, peneliti bermaksud melakukan penelitian untuk melihat pengaruh model pembelajaran $5 \mathrm{E}$ terhadap perubahan konsep Hukum Newton siswa kelas $X$ SMA Negeri 6 Palu.

\section{METODE PENELITIAN}

Jenis penelitian yang digunakan adalah jenis penelitian dengan rancangan eksperimen kuasi (quasi-experimental design) yaitu penelitian dengan cara membandingkan kelompok.

Adapun desain penelitian yang digunakan yaitu the non ekivalen pretest-posttest design. Desain penelitian yang digunakan dapat dilukiskan seperti pada Tabel 1. 
Tabel 1 Rancangan Prates-Pascates yang tidak Ekuivalen

\begin{tabular}{|c|c|c|c|}
\hline Kelompok & Prates & Perlakuan & Pascates \\
\hline Eksperimen & $\mathrm{O}$ & $\mathrm{X}_{1}$ & $\mathrm{O}$ \\
\hline Kontrol & $\mathrm{O}$ & $\mathrm{X}_{2}$ & $\mathrm{O}$ \\
\hline
\end{tabular}

Keterangan:

$\mathrm{X}_{1}$ : Perlakuan dengan model pembelajaran $5 \mathrm{E}$

$\mathrm{X}_{2}$ : Perlakuan dengan model pembelajaran konvensional

O : Prates/Pascates

Penelitian dilakukan di SMA Negeri 6 Palu. Populasi dalam penelitian ini adalah seluruh siswa kelas $X$ SMA Negeri 6 Palu tahun pelajaran 2014/2015 yang terdiri dari 4 kelas. Sampel dalam penelitian ini adalah kelas XC dan XD. Teknik pengumpulan sampel yang digunakan adalah purposive sampling, yaitu teknik penentuan sampel dengan pertimbangan tertentu.

\section{HASIL DAN PEMBAHASAN}

1. Hasil Penelitian

A. Uji Peningkatan Perubahan Konsep tentang Hukum Newton

Peningkatan perubahan konsep siswa tentang hukum Newton yang diperoleh dari kelas eksperimen (menggunakan model pembelajaran 5E) dan kelas kontrol (menggunakan model pembelajaran konvensional) yang dihitung menggunakan persamaan $\mathrm{N}$-Gain disajikan pada Tabel 2 .

Tabel 2 Hasil Uji $\mathrm{N}$-Gain Kelas Eksperimen dan Kelas Kontrol

\begin{tabular}{|c|c|c|c|}
\hline Uraian & Tes Awal & Tes Akhir & $N$-Gain \\
\hline Eksperimen & 4,86 & 20,36 & 61,40 \\
\hline Kontrol & 5,92 & 14,14 & 34,18 \\
\hline
\end{tabular}

Berdasarkan data Tabel 2 dapat dilihat bahwa peningkatan perubahan konsep untuk kelas eksperimen berada pada ketergori sedang begitupun untuk kelas kontrol berada pada ketegori sedang tetapi jika ditinjau secara kuantitatif untuk kelas eksperimen lebih unggul dari kelas kontrol dengan nilai rata-rata $\mathrm{N}$-Gain sebesar $61,40 \%$ sedangkan untuk kelas kontrol $34,18 \%$.
Data tersebut disajikan kembali dalam diagram agar lebih memberikan gambaran detail dan menyeluruh tentang hasil penelitian.

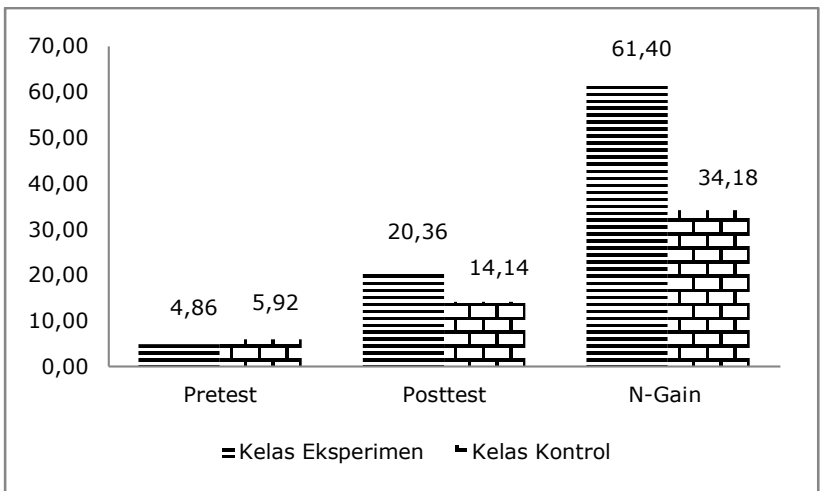

Gambar 1 Diagram Perbandingan Skor Rata-rata Tes awal, Tes akhir dan N-gain Tes Pemahaman Konsep antara Kelas Eksperimen dan Kelas Kontrol

B. Uji Hipotesis

Uji hipotesis ini digunakan untuk memastikan apakah hipotesis yang diajukan dapat diterima atau ditolak. Uji hipotesis ini menggunakan uji statistik nonparametrik uji Mann-Whitney.

Tabel 3 Uji Hipotesis Kelas Eksperimen dan Kelas Kontrol

\begin{tabular}{|l|c|c|c|c|}
\hline \multicolumn{1}{|c|}{ Kelas } & $\overline{\mathrm{X}}$ & $\mathrm{U}_{\text {hitung }}$ & $\begin{array}{c}\mathrm{U}_{\text {tabel }} \\
(\alpha=0,05)\end{array}$ & Keputusan \\
\cline { 1 - 2 } Eksperimen & 61,40 & \multirow{2}{*}{4,50} & 71,00 & $\mathrm{H}_{1}$ diterima \\
\cline { 1 - 2 } Kontrol & 34,18 & & & \\
\hline
\end{tabular}

Berdasarkan Tabel 3 Nilai $U_{\text {hitung }}<U_{\text {tabel }}$ atau $4,50<71,00$. Hal ini menunjukkan bahwa $U_{\text {hitung }}$ berada diluar daerah penerimaan Ho. Dengan demikian dapat disimpulkan bahwa rata-rata perubahan konsep antara siswa yang mendapatkan pembelajaran $5 \mathrm{E}$ lebih baik daripada siswa yang mendapatkan model pembelajaran konvensional sehingga dapat dikatakan terdapat pengaruh perubahan konsep siswa sesudah diterapkannya model pembelajaran $5 \mathrm{E}$.

\section{Hasil Observasi}

Data aktivitas guru dan siswa diperoleh melalui observasi yang dilakukan oleh seorang observer setiap pertemuan menggunakan lembar observasi. Hasil observasi aktivitas guru dan siswa dapat dilihat pada Tabel 4 berikut:

Tabel 4 Hasil Observasi Aktivitas Guru dan Siswa Kelas Eksperimen

\begin{tabular}{|c|c|c|}
\hline Pertemuan & $\begin{array}{c}\text { Rerata Skor (\%) } \\
\text { Siswa }\end{array}$ & $\begin{array}{c}\text { Rerata Skor } \\
(\%) \\
\text { Guru }\end{array}$ \\
\hline Pertemuan 1 & $81,06 \%$ & $85,29 \%$ \\
\hline
\end{tabular}




\begin{tabular}{|c|c|c|} 
Pertemuan 2 & $84,85 \%$ & $86,03 \%$ \\
\hline Pertemuan 3 & $86,29 \%$ & $87,50 \%$ \\
\hline Rerata skor (\%) & $86,07 \%$ & $86,27 \%$ \\
\hline
\end{tabular}

Berdasarkan tabel diatas, dapat dilihat aktivitas guru dan siswa pada kelompok eksperimen termasuk dalam kategori baik.

\section{Jawaban Hasil Tes}

Untuk mengetahui gambaran konsep Hukum Newton dalam penelitian digunakan instrumen penelitian berupa tes sejumlah 6 butir soal essai. Berikut ditampilkan beberapa kutipan jawaban siswa pada kelas eksperimen dengan menggunakan model pembelajaran 5E tentang konsep Hukum Newton untuk melihat perubahan konsep pada siswa melalui tes pemahaman konsep.

a) Soal tentang Konsep Hukum I Newton (1)

Diberikan sebuah kasus tentang sebuah mobil yang sedang berjalan dan tiba-tiba supir mobil menginjak rem secara mendadak. Siswa diminta menyebutkan apa yang terjadi dan menjelaskan (Lampiran A soal No.1). Untuk lebih jelasnya, perubahan konsep K-05 mengenai konsep Hukum I Newton dapat dilihat pada Tabel 5.

Tabel 5 Perbandingan jawaban pretest dan posttest K-05

\begin{tabular}{|c|c|}
\hline & Jawaban siswa \\
\hline Pretest & $\begin{array}{l}\text { terhentak kedepan / bergerak ke clepan karena adanga } \\
\text { gaya tark / gaya dorong }\end{array}$ \\
\hline Posttest & $\begin{array}{l}\text { Bergerak, ke depan (Karena mobul bergerak ke depan, kital } \\
\text { mempartahankan q erak ke depan, schingaa berlakulah } \\
\text { Hetkim Newton } 1 \text { ). }\end{array}$ \\
\hline
\end{tabular}

b) Soal tentang Konsep Hukum I Newton (2)

Diberikan sebuah kasus tentang sebuah benda yang bergerak, siswa diminta untuk mengidentifikasi kecepatan benda pada saat tidak ada gaya luar yang bekerja (Lampiran A soal No.2). Untuk lebih jelasnya, perubahan konsep K-05 dapat dilihat pada Tabel 6.

Tabel 6 Perbandingan jawaban pretest dan posttest K-05

\begin{tabular}{|c|c|}
\hline & Jawaban Siswa \\
\hline Pretest & $\begin{array}{c}\frac{v \frac{s}{t}}{t}=\frac{\text { Meter }}{\text { sokon }} \mathrm{m} / \mathrm{s} \\
\frac{50}{10}=500 \mathrm{~m} / \mathrm{s}\end{array}$ \\
\hline Posttest & $\begin{array}{l}\text { Kecapatannya tetap so } \mathrm{m} / \mathrm{s} \text {. Karena Hdak ada gaya } \\
\text { yeng memengaruhinya fad berlake Hukem Newton } 1\end{array}$ \\
\hline
\end{tabular}

c) Soal tentang Konsep Hukum II Newton

Diberikan contoh kasus mendorong lemari kosong, siswa diminta untuk menjelaskan mengapa kecepatannya meningkat (Lampiran A soal No.3). Untuk lebih jelasnya, perubahan konsep K-03 mengenai konsep kelajuan dapat dilihat pada Tabel 7.

Tabel 7 Perbandingan jawaban pretest dan posttest K-03

\begin{tabular}{|c|c|}
\hline & Jawaban Siswa \\
\hline \multirow[t]{3}{*}{ Pretest } & Karena, lemari yang hosong akan terasa nugan. \\
\hline & sedangkan lemari yang volumenya lebih besar \\
\hline & bergeraknya agak sedikit lambat. \\
\hline \multirow[t]{4}{*}{ Posttest } & karha gaya yang diberikan besar sehingga lemari \\
\hline & kosong tersebut semakin cepat, sedangngkan lemari \\
\hline & yang volumenya lebih besai lombat kasena beban yang \\
\hline & didorong Berat. \\
\hline
\end{tabular}

d) Soal tentang Konsep Hukum III Newton (1) Disajikan sebuah gambar buku diam yang diletakkan di atas meja, siswa diminta mengidentifikasi gaya-gaya yang bekerja. Pada soal Nomor 4 banyak siswa menjawab tidak ada gaya yang bekerja tanpa memberikan alasan (Lampiran A soal No.4). Untuk lebih jelasnya, perubahan konsep K-08 dapat dilihat pada Tabel 8.

Tabel 8 Perbandingan jawaban pretest dan posttest K-08

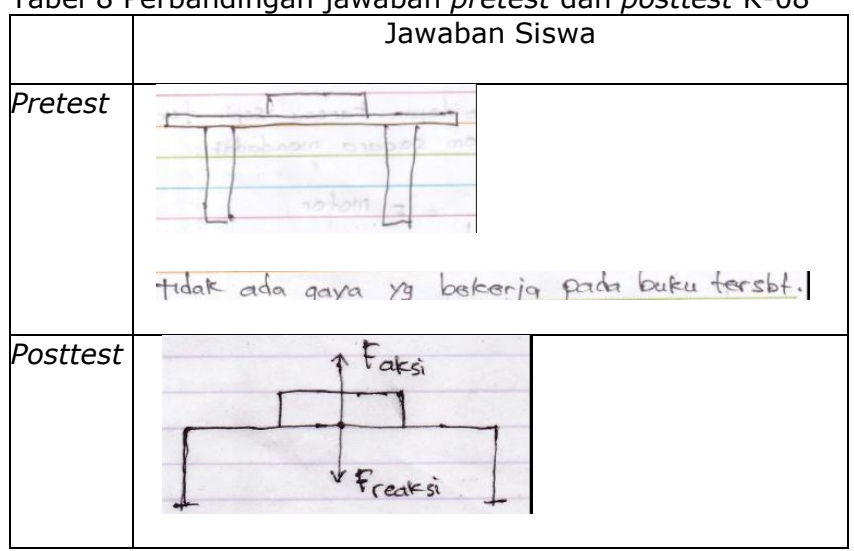

e) Soal tentang Konsep Hukum III Newton (2)

Disajikan sebuah gambar balok yang digantungkan, siswa diminta mengidentifikasi gaya-gaya yang bekerja (Lampiran A soal No.5). Untuk lebih jelasnya, perubahan konsep $\mathrm{K}-14$ mengenai konsep aksi reaksi dapat dilihat pada Tabel 9. 
Tabel 9 Perbandingan jawaban pretest dan posttest K-14

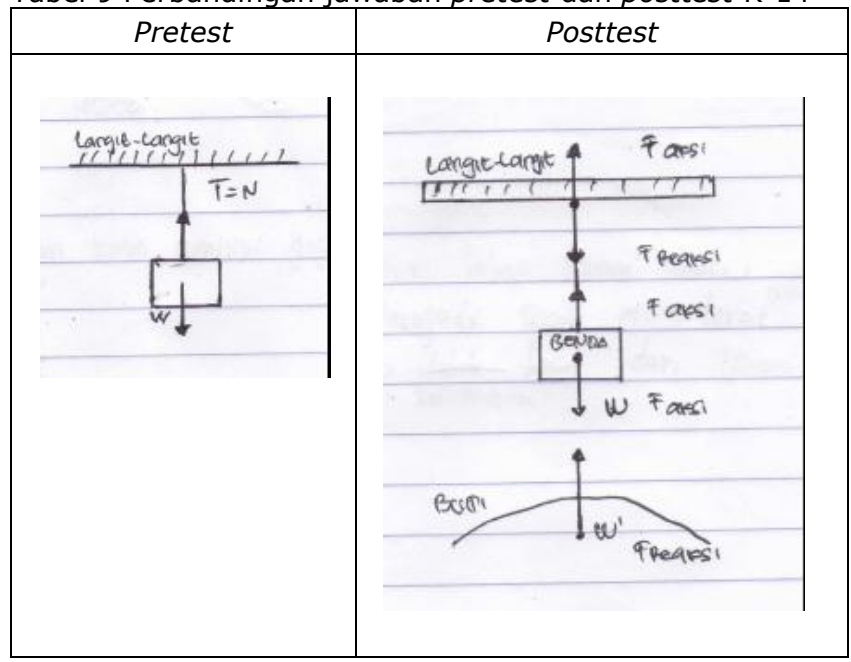

f) Soal tentang Konsep Hukum II dan Hukum III Newton

Diberikan sebuah kasus tentang seorang tukang batu yang diberi tugas menarik gerobak untuk memindahkan sebongkahan batu, siswa diminta untuk mengidentifikasi asumsi yang ada (Lampiran A soal No.6). Untuk lebih jelasnya, perubahan konsep K-09 mengenai konsep Hukum II dan Hukum III Newton dapat dilihat pada Tabel 10.

Tabel 10 Perbandingan jawaban pretest dan posttest K-09

\begin{tabular}{|c|c|}
\hline & Jawaban Siswa \\
\hline \multirow[t]{2}{*}{ Pretest } & Setuju dengan pendapat tukang \\
\hline & batu karena jika kita memberi qaya. \\
\hline \multirow[t]{5}{*}{ Posttest } & Tidak, memang benarada aksi dan reaksi \\
\hline & gerobak dan fukang batu tapikanilo juga ad a \\
\hline & gaya aksi dan reaksi kaki terhadap lantai \\
\hline & dan roda terhadap lantaino sehingag 3 \\
\hline & gerobakpun dapat bergerak ke depain. \\
\hline
\end{tabular}

\section{Pembahasan}

Sebelum diberikan perlakuan, siswa pada kelas eksperimen dan kelas kontrol diberikan tes awal untuk mengetahui kemampuan awal siswa. Selanjutnya, siswa yang berada di kelas eksperimen menerima materi dengan model pembelajaran $5 \mathrm{E}$, sedangkan siswa pada kelas kontrol menerima materi dengan pembelajaran konvensional dengan model pembelajaran konvensional. Selanjutnya kedua kelas tersebut diberikan tes akhir untuk melihat pengaruh model pembelajaran 5E terhadap perubahan konsep siswa.

Pada saat dilakukan tes akhir diperoleh skor rata-rata seperti pada Gambar 1 yaitu untuk kelas eksperimen sebesar 20,36 dengan $\mathrm{N}$-gain $61,40 \%$ dan kelas kontrol sebesar 14,14 dengan $\mathrm{N}$-gain sebesar $34,18 \%$. Dari skor $\mathrm{N}$-gain tersebut ditunjukkan bahwa kelas eksperimen yang menerima materi dengan model pembelajaran $5 \mathrm{E}$ memperoleh peningkatan perubahan konsep lebih tinggi daripada kelas kontrol yang menerima materi dengan model pembelajaran konvensional. Namun demikian skor $N$-gain kedua kelas tersebut masih termasuk dalam kategori sedang.

Perbandingan persentase peningkatan perubahan konsep siswa pada setiap soal dapat dilihat pada Gambar 2.

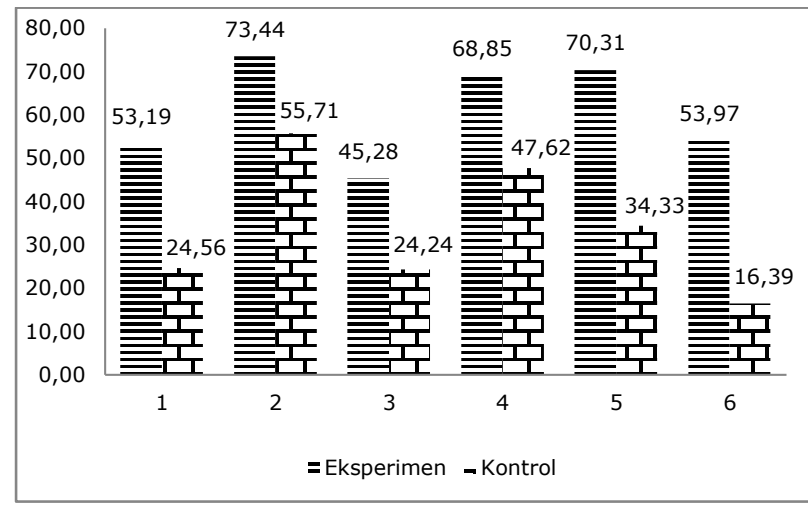

Gambar 2. Diagram Perbandingan N-Gain pada Kelas Eksperimen dan Kelas Kontrol untuk Setiap soal

Berdasarkan grafik pada Gambar 2, dapat diketahui bahwa peningkatan perubahan konsep kelas eksperimen lebih baik daripada kelas kontrol sehingga dapat dikatakan terdapat pengaruh perubahan konsep siswa sesudah diterapkannya model pembelajaran $5 \mathrm{E}$.

Selama dalam pembelajaran siswa dalam kelompok-kelompok kecil setiap kelompok terdiri dari empat atau lima siswa dan anggota kelompok sifatnya tetap. Dengan mengelompokkan siswa ke dalam kelompokkelompok kecil, memberi peluang untuk mendiskusikan masalah yang dihadapi, saling tukar ide antar siswa, dan memperdebatkan alternatif pemecahan masalah. Selain itu, siswa dimungkinkan mampu menyelesaikan masalah yang lebih baik dibanding jika mereka bekerja sendiri ${ }^{[8]}$. 
Pada tahap pertama model pembelajaran 5E yaitu tahap engagement (pembangkit minat). Tahap ini bertujuan untuk merangsang pengetahuan awal siswa dengan memberikan pertanyaan yang berhubungan dengan kehidupan sehari-hari. Pada tahap ini siswa mulai aktif dalam menjawab pertanyaan, hal ini dapat terlihat dari antusias semua siswa dalam menjawab. Hasil ini sesuai dengan penelitian sebelumnya, yang menyatakan bahwa pada tahap engagement (pembangkit minat) dapat membangkitkan semangat siswa dalam memulai pembelajaran dan membuat siswa lebih aktif dalam pembelajaran ${ }^{[9]}$.

$$
\text { Selanjutnya tahap exploration }
$$

(eksplorasi), pada tahap ini siswa berkelompok untuk melakukan ekperimen. Siswa menjadi lebih aktif sedangkan guru hanya mengarahkan siswa untuk dapat menemukan konsep yang dimaksud. Hasil ini sesuai dengan penelitian sebelumnya, kelompok yang melakukan pengamatan melalui eksperimen hasilnya lebih baik dari kelompok yang menerima materi dari gambar karena melalui eksperimen siswa terlibat langsung dalam kegiatan untuk menemukan suatu konsep dan melibatkan lebih banyak indera ${ }^{[10]}$. Kemudian dilanjutkan menyelesaikan permasalahan yang terdapat didalam Lembar Kerja Siswa (LKS).

Tahap selanjutnya adalah tahap explanation (penjelasan), pada tahap ini siswa akan memberikan perwakilan dari setiap kelompok untuk maju mempresentasikan hasil yang diperoleh pada tahap exploration. Siswa akan menjelaskan konsep dari ekperimen yang telah dilakukan dengan menggunakan bahasa mereka sendiri atau bahasa yang mereka pahami. Jika masih terdapat jawaban yang kurang tepat maka guru akan meluruskan jawaban siswa tersebut.

Tahap yang keempat yaitu elaboration (elaborasi) yang bertujuan agar siswa dapat menerapkan konsep yang baru saja mereka pelajari dalam situasi yang berbeda atau konteks yang berbeda. Pada tahap ini guru memberikan pertanyaan kepada siswa dan didiskusikan secara berkelompok. Siswa akan lebih mudah dalam menjawab pertanyaan karena mereka telah mengetahui konsep yang dipelajari. Selain itu, siswa akan mengetahui contoh penerapan dari konsep yang telah dipelajari.

Selama kegiatan diskusi berlangsung guru memantau jalannya diskusi, memberikan bimbingan serta motivasi agar siswa aktif terlibat dalam kegiatan pemecahan masalah di kelompok masing-masing. Hal ini sesuai dengan penelitian sebelumnya, yaitu guru memberikan motivasi agar siswa aktif berdiskusi karena hasil pemikiran beberapa siswa akan lebih baik daripada hasil pemikiran satu siswa saja ${ }^{[11]}$.

Tahap yang terakhir adalah tahap evaluation (evaluasi), pada tahap ini guru memberikan kuis. Dari nilai yang diperoleh siswa, terlihat perubahan konsep siswa mengalami peningkatan. Hal ini juga memperkuat data lain yang diperoleh dari hasil posttest.

Berbeda halnya dengan kelas eksperimen, pada kelas kontrol proses pembelajarannya menggunakan metode konvensional yaitu ceramah dan tanya jawab. Pada metode ini siswa cenderung bersifat pasif, hanya menerima semua yanng dijelaskan oleh guru dan mencatat hal-hal yang dianggap penting di papan tulis. Sementara kegiatan guru adalah menyampaikan materi hukum Newton secara lisan. Selain itu ketika siswa diberikan kesempatan untuk mengajukan pertanyaan, mereka canggung untuk bertanya. Ketidak aktifan siswa dalam proses pembelajaran menyebabkan siswa kurang termotivasi untuk menemukan konsep terkait dengan materi yang diberikan. Selain itu, menyebabkan materi yang diterima kurang efektif sehingga mudah terlupakan dan pada akhirnya perubahan konsep siswa kurang berkembang.

Kelebihan dari model pembelajaran 5E dibandingkan dengan model pembelajaran konvensional adalah keaktifan siswa. Karena dengan menggunakan model pembelajaran 5E siswa memiliki kesempatan untuk menyelidiki sendiri, menemukan konsep, dan menjelaskan konsep dengan bahasa yang lebih mereka pahami. Hal ini sejalan dengan penelitian yang sebelumnya yang menyatakan bahwa model pembelajaran $5 \mathrm{E}$ merupakan model yang menuntut aktifitas maupun kreativitas siswa dalam belajar diantaranya membuat siswa lebih termotivasi dalam bekerja sama ${ }^{[6]}$.

Berdasarkan analisis data, perubahan konsep yang terjadi pada siswa cukup baik. Namun, walaupun semua siswa mengalami perubahan konsep secara baik masih terdapat miskonsepsi pada beberapa konsep. Hal ini disebabkan siswa memiliki konsep awal dan ini sangat bersifat resisten. Hasil ini didukung dengan pernyataan yang menyatakan konsep yang bertentangan dengan teori atau konsep awal siswa tidak selalu diterima. Siswa yang tidak menerima, tidak akan menghasilkan perubahan konsep secara kuat, sedangkan bila menerima akan menghasilkan 

perubahan konsep secara kuat atau
akomodasi $^{[12]}$.

\section{KESIMPULAN}

Berdasarkan hasil dan analisis data penelitian maka dapat disimpulkan bahwa terdapat pengaruh model pembelajaran 5E terhadap perubahan konsep hukum Newton siswa kelas X SMA Negeri 6 Palu.

\section{DAFTAR PUSTAKA}

[1] Dahar, R.W. (2011). Teori-Teori Belajar \& Pembelajaran. Jakarta: Erlangga.

[2] Posner, G. et al. (1982). Accommodation of a scientific conception: Toward a theory of conceptual change. Science Education, 66(2), 221-227.

[3] Hewson, P.W. dan Thorley, N.R. 1989. The Conditions of Conceptual Change in the Classroom. Int. J. Sce. Educ., 11 special issue: 541-553.

[4] Meidahrianti. (2014). "Pengaruh Strategi Pembelajaran Konflik Kognitif Terhadap Perubahan Konseptual Siswa Pada Materi Listrik Dinamis Di SMA Negeri 1 Tanjung Batu". Jurnal Inovasi dan Pembelajaran Fisika. Vol.1 No.1, Mei 2014.

[5] Wena, M. (2009). Strategi Pembelajaran Inovatif Kontemporer: Suatu Tinjauan Konseptual Operasional. Jakarta: Bumi Aksara.

[6] Holijah. (2011). Peningkatan Pemahaman Konsep Fisika Melalui Model Pembelajaran Learning Cycle (LC) Pada Siswa Kelas VIIIC SMP Negeri 19 Palu. Palu: FKIP Universitas Tadulako.

[7] Karim, L.A. (2012). Penerapan Model Learning Cycle Untuk Meningkatkan Penguasaan Konsep Getaran Dan Gelombang Pada Kelas VIII SMPN 9 Palu. Palu: FKIP Universitas Tadulako.

[8] Erman, S. (2003). Strategi Pembelajaran Matematika Komtemporer. Bandung: JICA-UPI.

[9] Kulsum, U. dan Hindarto, N. (2011). "Penerapan Model Learning Cycle Pada Sub Pokok Bahasan Kalor Untuk Meningkatkan Keaktifan Dan Hasil Belajar Siswa Kelas VII SMP". Jurnal Pendidikan Fisika Indonesia. 7: 128-133.

[10] Nurjannah, F. (2014). Analisis Kemampuan Generik Siswa Melalui Kegiatan Praktikum Fotosintesis (Penelitian Deskriptif pada Kelas VIII di SMP ALHasra Depok). Skripsi pada Fakultas Ilmu Tarbiyah dan Keguruan UIN Syarif Hidayatullah. Jakarta: Tidak dipublikasikan.

[11] Lie, Anita. (2008). Cooperative Learning: Mempraktikkan Cooperative Learning di RuangRuang Kelas. Jakarta: Gramedia.

[12] Suparno, P. (2005). Miskonsepsi dan Perubahan Konsep dalam Pendidikan Fisika. Jakarta: PT Grasindo. 
